\title{
PENGARUH YOGA TERHADAP KUALITAS TIDUR LANSIA (ELDERLY)
}

\author{
Sisilia Indriasari W*1, Ramadhan Andhika Putra ${ }^{2}$ \\ STIKES Katolik St. Vincentius A Paulo Surabaya Jurusan Fisioterapi
}

\begin{abstract}
Background: The aging process is followed by physiological changes that may affect the sleep quality of elderly. The phenomenon found in Posyandu Lansia (Elderly Health Center) of RW 03 Jagir sidomukti revealed the decrease of sleep quality in elderly such as insomnia, short period of sleep (5 hours per day), and difficulty in falling asleep after waking up. Methods: The purpose of this research was to analyze the influence of yoga on the sleep quality of elderly in Posyandu Lansia RW 03 Kelurahan Jagir Surabaya. This research applied pre-experimental one group pre-post test design. The sample of this research is elderly Posyandu Lansia RW 03 Jagir Surabaya that was taken using simple random sampling, with a total sample of 36 respondents. The independent variable of this research is yoga and the dependent variable is the sleep quality of elderly. The instrument applied in this research is PSQI for sleep quality. Results: Showed that $66.6 \%$ of the elderly had poor sleep quality before yoga and $77.7 \%$ had good sleep quality after yoga. The Wilcoxon rank test results obtained $p=0,000$, with the value $\alpha=0.05$ where $p<\alpha H_{0}$ rejected. This indicates that yoga has an influence on the sleep quality of elderly. Based on the research result, it is suggested for the headman of RW 03 Kelurahan Jagir Surabaya and Puskesmas Jagir (Jagir Health Center) to hold yoga exercises regularly. Conclusion: It is also suggested for the health center to train their own yoga instructors so that they may instruct yoga for elderlies who cannot reach the health center in order to improve their sleep quality.
\end{abstract}

Keywords: Yoga, Sleep Quality Of Elderly

\section{PENDAHULUAN}

Proses penuaan biasanya di gambarkan dengan perubahan fisiologis yang bisa mempengaruhi kualitas tidur lansia (Schalet, A. T., Santelli, J. S., Russell, S. T, dkk, 2014). Penyebab perubahan tidur dan terbangun yaitu perubahan pada lobus frontal lansia pada proses penuaan (Mass, 2011). Lansia mengalami periode penurunan tidur normal pada NREM 3 dan hampir tidak memiliki tahap 4 atau tidur dalam. Waktu tidur normal lansia adalah 7-8 jam per hari, dan dikatakan penurunan kualitas tidur apabila tidur lansia 5-6 jam. Lansia akan di kategorikan memiliki gangguan tidur bila tidur selama $<5$ jam per hari (National Sleep Foundation, 2015). Fenomena yang saat ini terjadi di masyarakat banyak lansia yang mengalami penurunan kualitas tidur seperti susah tidur, dan tidur di bawah 5 jam per hari.

Menurut data Depkes Indonesia, lansia yang mengalami gangguan tidur per tahun sekitar 750 orang dan prevalensi gangguan tidur pada lansia cukup tinggi yaitu sekitar $50 \%$ dari 18,1 juta pada tahun 2009 (Depkes RI, 2011). Hasil penelitian kualitas tidur lansia di Balai Rehabilitasi Sosial "Mandiri Semarang 
menunjukkan bahwa 29 reponden $(29,9 \%)$ memiliki kualitas tidur baik dan 68 responden $(70,1 \%)$ memiliki kualitas tidur buruk. Hasil penelitian ini dapat disimpulkan bahwa secara keseluruhan kualitas tidur lansia buruk (Kusnul, 2012). Hasil survey awal yang di lakukan pada 4 Januari 2017 di kelompok lansia yang tinggal di RW 03 Kelurahan Jagir didapatkan hasil bahwa 6 dari 10 lansia mengalami penurunan kualitas tidur berdasarkan nilai PSQI dengan skor $<5$.

Adapun faktor- faktor fisiologis seperti penyakit fisik, obat-obatan, gaya hidup, nutrisi lansia dan faktor psikologis stress, depresi, maupun lingkungan dapat mengubah kualitas dan kuantitas tidur (Potter, 2010). Stress emosional menyebabkan seorang menjadi tegang dan seringkali mengarah frustasi apabila tidak tidur. Stress juga menyebabkan seseorang mencoba terlalu keras untuk tertidur, sering terbangun selama siklus tidur. Lansia yang mengalami masalah perasaan depresi, sering juga mengalami perlambatan untuk jatuh tertidur, munculnya REM secara dini, seringkali terjaga peningkatan total waktu tidur, perasaan tidur yang kurang, dan terbangun cepat (Potter, 2010).

Penurunan kualitas tidur dapat menyebabkan penurunan daya tahan tubuh seseorang. Selain itu juga mengakibatkan penurunan kemampuan mental, kemampuan otak, dan kreativitas untuk menggunakan data hafalan. Secara psikologis, cenderung mengalami gangguan stabilitas emosional. Orang mudah marah, kecewa, sedih, serta tidak bergairah (lemah, letih, lesu) (Prasadja, 2009).

Salah satu upaya untuk meningkatkan kualitas tidur dengan berolahraga 2 jam atau lebih sebelum tidur dapat meningkatkan relaksasi dan menurunkan kelelahan (Potter, 2010). Salah satu olahraga itu dengan yoga yang salah satu manfaatnya yaitu memperbaiki pola tidur (Wiadnyana, 2010). Senam yoga mampu merangsang penurunan aktifitas saraf simpatis dan peningkatan aktifitas saraf para simpatis yang berpengaruh pada penurunan hormon adrenalin, norepinefrin dan kotekolamin serta vasodilatasi pada pembuluh darah yang mengakibatkan transport oksigen ke seluruh tubuh terutama otak lancar sehingga dapat menurunkan tekanan darah dan nadi menjadi normal. Pada kondisi ini akan meningkatkan relaksasi lansia. Selain itu sekresi melatonin yang optimal dan pengaruh beta endhorphin dan membantu peningkatan pemenuhan kebutuhan tidur lansia (Cahyono, 2012). Pemberian senam yoga terhadap kualitas tidur lansia dapat meningkatan pemenuhan kebutuhan tidur pada lansia (Sukartini, 2009). Tujuan dari penelitian ini adalah untuk menganalisis pengaruh antara yoga dengan kualitas tidur lansia (elderly) di RW 03 Kelurahan Jagir Surabaya.

\section{METODE PENELITIAN}

Desain penelitian yang di gunakan adalah desain menggunakan pra eksperimental dengan rancangan (one group pra-post test design) pada lansia yang menjadi anggota Posyandu Lansia RW 03 Kelurahan Jagir Surabaya berdasarkan kriteria inklusi yaitu, bersedia menjadi responden, berumur 60-74 tahun, tidak memiliki keterbatasan gerak, Bisa membaca dan menulis, hadir dalam kegiatan Posyandu. Teknik sampling dalam penelitian ini menggunakan Teknik simpe random sampling dengan jumlah sampel 36 orang. Data dianalisis dengan 
menggunakan uji statistic Wilcoxon $\alpha=0,05$.

dengan batasan kemaknaan $\mathrm{p}<\alpha$ dimana

\section{HASIL PENELITIAN}

Tabel 1. Karakteristik Responden di Posyandu Lansia RW 03 Kelurahan Jagir

\begin{tabular}{lcc}
\hline Variabel & Frekuensi (n) & Presentase (\%) \\
\hline Usia Lansia (tahun) & 36 & 100 \\
60-74 (elderly) & & \\
Menderita Penyakit & 10 & 27,78 \\
Tidak ada & 2 & 5,56 \\
Asma & 13 & 36,1 \\
Hipertensi & 7 & 19,4 \\
Diabetes & 2 & 5,56 \\
Asam urat & 2 & 5,56 \\
Stroke & & \\
Konsumsi Teh/Kopi & 22 & 61,1 \\
Ya & 14 & 38,89 \\
Tidak & & \\
Olahraga & 19 & 52,78 \\
$<3 x / m i n g g u$ & 17 & 47,22 \\
$>3 x / m i n g g u$ & &
\end{tabular}

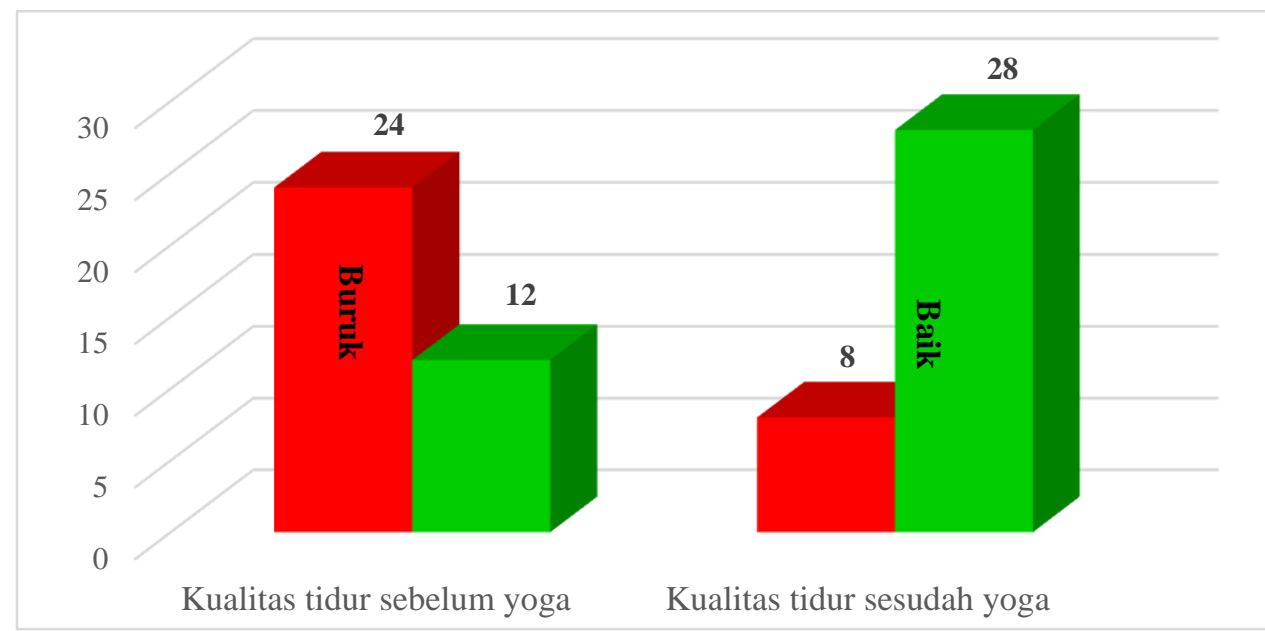

Grafik.1 Kualitas Tidur Sebelum dan Sesudah dilakukan Yoga Posyandu Lansia RW 03 Kelurahan Jagir Sidomukti

Hasil uji statistik menunjukkan $\mathrm{p}=$ 0,000 , dengan nilai $\alpha=0,05$ dimana $\mathrm{p}<\alpha$ $\mathrm{H}_{0}$ ditolak, yang menunjukkan bahwa ada pengaruh yoga terhadap kualitas tidur lansia di posyandu lansia RW 03 Jagir Surabaya

\section{PEMBAHASAN}

Berdasarkan hasil penelitian sebelum dilakukan yoga terdapat 12 responden dengan kualitas tidur baik dan 24 responden dengan kualitas tidur buruk. Dari 24 responden yang memiliki kualitas 
tidur yang buruk didapatkan 24 responden menderita penyakit yang terdiri dari 13 responden menderita hipertensi, 5 responden menderita diabetes, 2 responden menderita stroke dan asma dan 1 responden menderita asam urat. Menurut Stanley (2006) setiap penyakit fisik yang menyebabkan nyeri, ketidaknyamanan fisik (misalnya kesulitan bernapas) dapat menyebabkan masalah tidur. Penyakit pernapasan seringkali mempengaruhi tidur, mereka seringkali tidak dapat tidur tanpa memakai dua atau tiga bantal untuk meninggikan kepala mereka. Hipertensi seringkali menyebabkan terbangun pada pagi hari. Terdapat kesesuaian antara fakta dan teori dimana lansia yang menderita penyakit asam urat mereka sering mengeluhkan nyeri pada saat tertidur dan sering terbangunnya lansia ini pada saat malam hari. Begitu juga dengan penderita diabetes sering terbangun malam hari hanya untuk berkemih. Keluhan-keluhan dari penyakit lansia tersebut dapat menyebabkan gangguan tidur pada lansia yang akhirnya menyebabkan kualitas tidur lansia menjadi buruk.

Berdasarkan hasil penelitian setelah dilakukan yoga 24 responden dengan kualitas tidur yang buruk sebanyak 18 responden yang mengkonsumsi teh/kopi. Menurut Weinberg (2009) jika sejumlah besar kafein dikonsumsi selama beberapa hari, perpanjangan aktivitas kafein akan meningkatkan kadarnya dalam darah, yang berujung pada pemunculan efek samping yang tidak diinginkan, termasuk gangguan tidur. Menurut hasil penelitian Kadita (2017) dalam jurnal penelitian "Hubungan Konsumsi Kopi Dan ScreenTime Dengan Lama Tidur Dan Status Gizi Pada Dewasa" mengkonsumsi kopi 3 jam sebelum tidur dapat mengurangi lama tidur hingga 3 jam. Hal ini dapat terjadi karena ketika kafein masuk ke tubuh, kafein akan menghambat pelepasan hormon adenosin yang berfungsi sebagai relaksasi. Susunan rantai kafein yang hampir sama dengan hormon adenosin menyebabkan kafein masuk ke reseptor adenosin dan menjadi reseptor adenosin antagonis. Adenosin antagonis tersebut kemudian masuk ke dalam saraf simpatis yang terdapat dopamin, sehingga tekanan darah, denyut jantung, kewaspasdaan meningkat dan menjadi aditif dengan kafein. Konsentrasi kafein akan maksimal di dalam tubuh setelah 6 jam setelah konsumsi dan efek puncak kafein terjadi selama 15- 45 menit setelah konsumsi. Peneliti berpendapat terdapat kesesuaian antara fakta dan teori dimana seseorang yang mengkonsumsi kopi mendekati waktu tidur yaitu mengkonsumsi pada jam sore dan malam, maka lama tidur subjek akan terganggu karena kerja kafein. Konsumsi kopi mendekati waktu tidur dapat meningkatkan latensi tidur dan menurunkan lama tidur mayoritas responden lansia sering mengkonsumsi teh/kopi. Sehingga banyak responden lansia mengeluhkan sulit untuk tidur di malam hari.

Berdasarkan hasil penelitian saat ini terdapat perubahan yang cukup signifikan, di dapatkan responden dengan kualitas tidur baik naik menjadi 24 dan kualitas tidur buruk turun menjadi 8 responden. Salah satu upaya untuk meningkatkan kualitas tidur dengan berolahraga 2 jam atau lebih sebelum tidur dapat meningkatkan relaksasi dan menurunkan kelelahan (Potter, 2009). Salah satu olaraga itu dengan yoga yang salah satu manfaatnya yaitu memperbaiki pola tidur (Wiadnyana, 2010). Menurut Cahyono (2012) senam yoga merangsang 
penurunan aktifitas saraf simpatis dan peningkatan aktifitas saraf para simpatis yang berpengaruh pada penurunan hormon adrenalin, norepinefrin dan kotekolamin serta vasodilatasi pada pembuluh darah yang mengakibatkan transport oksigen ke seluruh tubuh terutama otak lancar sehingga dapat menurunkan tekanan darah dan nadi menjadi normal. Pada kondisi ini akan meningkatkan relaksasi lansia. Selain itu sekresi melatonin yang optimal dan pengaruh beta endhorphin dan membantu peningkatan pemenuhan kebutuhan tidur lansia. sehingga lansia akan menjadi rileks dan mempercepat proses masuk fase NREM. Peneliti berpendapat terdapat kesesuaian fakta dan teori dimana yoga dapat mempengaruhi hipotalamus untuk meningkatkan produksi beta endorphin yaitu suatu morfin alami tubuh yang akan menyebabkan stabilitas emosi serta membuat rileks tubuh. Kondisi tenang dan rileks inilah yang akan mendorong lansia untuk memulai tidurnya sampai hingga masuk kedalam fase tidur. Selain itu efek daripada yoga adalah menurunkan ketegngan otot sehingga peredaran darah lancar, oksigen yang di bawa ke otak pun terpenuhi. Hal tersebut menunjang untuk memasuki fase tidur yang lebih dalam.

Kualitas tidur lansia sebelum dilakukan yoga sebanyak 12 responden memiliki kualitas tidur baik dan 24 responden memiliki kualitas tidur buruk. Setelah di berikan intervensi berupa yoga ada perbedaan yang cukup signifikan 28 responden memiliki kualitas tidur baik dan hanya 8 responden memiliki kualitas tidur yang buruk. Menurut peneliti, adanya kesesuaian antara teori dan praktek yang menyatakan bahwa yoga dapat memperbaiki pola tidur (Wiadnyana, 2010). Hal ini dapat di buktikan dengan hasil uji hipotesis dilakukan dengan menggunakan uji Wilcoxon dan dianalisis dengan menggunakan piranti lunak program SPSS 21 for Windows untuk mencari pengaruh yoga terhadap kualitas tidur pada lansia Posyandu Lansia di RW 03 Kelurahan Jagir Surabaya pada tanggal 15 Mei 2018 menunjukkan $\mathrm{p}=0,000$, dengan nilai $\alpha=$ 0,05 dimana $\mathrm{p}<\alpha \mathrm{H}_{0}$ ditolak, yang menunjukkan bahwa ada pengaruh yoga terhadap kualitas tidur lansia di posyandu lansia RW 03 Jagir Surabaya. Dibuktikan dengan nilai negative ranks sebanyak 23 yang bermakna terdapat penurunan skor PSQI sesudah di berikan yoga. Peneliti merasakan ada perbedaan yang signifikan pada lansia terlihat dari rasa nyaman dan pola tidur Menurut hasil penelitian Sukartini (2009) dalam jurnal "Latihan yoga Dapat Mempengaruhi Kebutuhan Tidur Lansia di Panti Werdha Mojopahit Mojokerto" Pemberian yoga berpengaruh terhadap kualitas tidur lansia karena yoga dapat membantu menjaga keseimbangan homeostasis tubuh melalui jalur HPA Axis yang dapat merangsang produksi $\beta$ endhorpin dan enkephalin yang merupakan neurotransmitter tidur. $\beta$ endorphin dan enkephalin dapat membuat tubuh menjadi rileks yang dapat menyebabkan perasaan senang sehingga lansia dapat tertidur. Peneliti berpendapat terdapat kesamaan penelitian jurnal dan peneltian saat ini yaitu Pemberian yoga berpengaruh terhadap pemenuhan kebutuhan tidur pada lansia baik secara kualitas maupun kuantitas, walaupun ada beberapa responden yang mengkonsumsi the atau kopi. Hal ini di sebabkan gerakan pada yoga lembut sehingga menstimulasi tubuh untuk memprodusi hormon endhorpin yang akan memberikan dampak tenang dan rileks, sehingga tubuh dapat 
mengatur keseimbangan sistem dalam tubuh. Suasana rileks menjadikan lansia dapat memusatkan pikiran sehingga stressor dari luar yang bersifat negatif atau kurang mendukung bagi lansia dapat dialihkan walau hanya sementara, sehingga membuat lansia dapat segera tertidur. Pada waktu lansia tertidur terjadi pelemasan otot dan penormalan sistem tubuh, sehingga sistem tubuh bisa kembali berfungsi efektif dan optimal yang dapat ditunjukkan oleh gejala dan tanda dari kondisi yang ditimbulkan oleh tidur yang berkualitas, seperti mampu berkonsentrasi, memiliki hubungan social yang luas, tidak merasa pusing setelah bangun tidur dan lain-lain. Pemberian yoga pada lansia dapat membantu lansia dalam memenuhi kebutuhan tidur.

\section{KESIMPULAN DAN SARAN}

Berdasarkan hasil penelitian maka dapat disimpulkan sebagai berikut, lebih dari 50\% (66,6\%) kualitas tidur buruk sebelum diberikan yoga, sebagian besar $(77,7 \%)$ kualitas tidur baik sesudah diberikan yoga. Hasil penelitian menunjukan ada pengaruh yoga terhadap kualitas tidur lansia di posyandu lansia RW 03 Kelurahan Jagir Surabaya.

Saran yang diberikan peneliti kepada Ketua RW agar bekerjasama dengan Puskesmas Jagir unit Geriatri untuk mengadakan senam yoga secara rutin dan membentuk instruktur dari posyandu yang dapat mengajarkan yoga kepada lansia lansia lain yang belum dapat di jangkau oleh posyandu lansia maupun puskesmas demi kualitas tidur yang baik

\section{DAFTAR RUJUKAN}

Cahyono, K. H., 2012. Pengaruh Senam Lansia Terhadap Kualitas Tidur Pada Lansia. Jurnal Geriatri, pp. 111.

Cloud, D., 2015. National Sleep Foundation Recommends New Sleep Time. National Sleep Foundation.

Depkes. (2011, Maret 15). Lansia di Indonesia. Retrieved from Departemen Kesehatan Republik Indonesia: Depkes.go.id

Kadita,Febriana. (2017). Hubungan Konsumsi Kopi Dan Screen-Time Dengan Lama Tidur Dan Status Gizi Pada Dewasa.Journal of Nutrition College,301-306.

Khusnul, K. \& Wahyu, H., 2012. Kualitas Tidur Lansia Balai Rehabilitasi Mandiri Semarang. Jurnal Nursing Studies, pp. 189-196.

Mass, Meridean. L, Buckwalter, Kathleen. C, Hardy, Mary. D et al. 2011.Nursing Care Of Older Adults, Jakarta: EGC

Cahyono, K. H., 2012. Pengaruh Senam Lansia Terhadap Kualitas Tidur Pada Lansia. Jurnal Geriatri, pp. 111.

Cloud, D., 2015. National Sleep Foundation Recommends New Sleep Time. National Sleep Foundation.

Depkes. (2011, Maret 15). Lansia di Indonesia. Retrieved from Departemen Kesehatan Republik Indonesia: Depkes.go.id

Kadita,Febriana. (2017). Hubungan Konsumsi Kopi Dan Screen-Time Dengan Lama Tidur Dan Status Gizi Pada Dewasa.Journal of Nutrition College,301-306. 
Khusnul, K. \& Wahyu, H., 2012. Kualitas Tidur Lansia Balai Rehabilitasi Mandiri Semarang. Jurnal Nursing Studies, pp. 189-196.

Mass, Meridean. L, Buckwalter, Kathleen. C, Hardy, Mary. D et al. 2011.Nursing Care Of Older Adults, Jakarta: EGC

Noorkasiani, 2012. Kesehatan Lanjut Usia dengan Pendekatan Asuhan Keperawatan. Jakarta: Salemba Medika.

Potter, P. A. (2005). Fundamental Keperawatan.Ed. 7. Alih bahasa: Marina Albar. 2010. Jakarta: Salemba Medika

Prasadja, A. (2009). Ayo Bangun. Jakarta: Penerbit Hikmah

Reny, Y. A., 2014. Asuhan Keperawatan Gerontik. Jakarta: CV. Trans Info media.

Sukartini, T., 2009. Latihan Yoga Dapat Memenuhi Kebutuhan Lansia. Nursing Journal, pp. 1-6.

Schalet, A. T., Santelli, J. S., Russell, S. T., Halpern, C. T., Miller, S. A., Pickering, S. S., Hoenig, J. M. (2014). Invited commentary: Broadening the evidence for adolescent sexual and reproductive health and education in the united states.Journal of Youth and Adolescence, 43(10), 1595-610. doi:http://dx.doi.org/10.1007/s10964 -014-0178-8.

Stanley, M. (2006). Buku Ajar Keperawatan Gerontik.Ahli bahasa: Nety Juniarti. 2006. Jakarta: EGC

Tamher, S. \& Noorkasiani, 2012. Kesehatan Usia Lanjut dengan Pendekatan Asuhan Keperawatan. Jakarta: Salemba Medika.

Weinberg, B. A, Bealer, B. K. (2009). The miracle of caffeine: manfaat tak terduga kaferin berdasarkan penelitian paling mutakhir. Bandung: PT Mizan Pustaka Wiadnyana, 2010. The Power of Yoga for Middle Age. Jakarta: Grasindo.

Widnyana, d. M., 2010. The Power Of Yoga for middle age. Jakarta : Grasindo. 